\title{
The Research of Non-contact Online Detection and Key Problem of
}

\section{Capsule Filling Machine}

\author{
Liu Ying ${ }^{1, a^{*}}$,Ning $\mathrm{Hai}^{2, \mathrm{~b}}$, Wang Guihe $\mathrm{e}^{3, \mathrm{c}}$ \\ ${ }^{1}$ College of Mechanical and Electronic Engineering, Eastern Liaodong University, Liaoning \\ 118000, China \\ ${ }^{2}$ College of Mechanical and Electronic Engineering, Eastern Liaodong University, Liaoning \\ 118000, China \\ ${ }^{3}$ College of Mechanical and Electronic Engineering, Eastern Liaodong University, Liaoning \\ 118000, China \\ aly72.9@163.com, bning.yp@163.com, cguihewang@163.com
}

Keywords: capsule filling machine, non-contact measurement, optical fiber sensor, synchronous detection

\begin{abstract}
Non-contact online detection is an online testing module for the capsule filling machine in China lack of capsule counting function, the module can display the number of actual production of qualified capsule in real-time. The analysis and research of the key technical problems in the module such as the choice of the sensor, signal acquisition and the synchronous detection matching on medicine machine movement and the best solution is given to ensure that the non-contact online detection system can achieve expected accurate counting function. The module has high promotion value for the application of automatic counting technology of capsule filling machines.
\end{abstract}

\section{Introduction}

With the demand for improving production efficiency and manufacturing accuracy of the capsule and the demand of the pharmaceutical enterprise for high speed and intelligent of the capsule filling machine, a new topic is put forward to the design, detection and control of capsule filling machine. Capsule filling machine non-contact online detection system uses optical fiber sensor to read the number of filling qualified capsule, then transmits the data to the microcontroller and shows the number of qualified capsule on digital tube to realize online real-time display function. Due to the complexity of capsule filling machine movement, there are both continuous movement and intermittent movement, both linear motion and rotational motion, detection technology has certain difficulty to be overcome[1]. To read the number of capsule accuratly and successfully and further improve the manufacturing precision of the machine and the production efficiency, the capsule filling machine non-contact online detection system and its key technology are analyzed for raising the precision of the machine count and achieving the goal of expected accurate measurement of the capsule. 


\section{The working principle of the capsule filling machine}

Capsule filling machine is an indispensable key equipment used in the pharmaceutical industry controlled by programmable controller which sets mechanical power, electricity power and pneumatic power as a whole[3]. Capsule filling machine is mainly composed of the main transmission mechanism, capsule conveying mechanism, slewing mechanism module and capsule filling mechanism.

Power of the main drive mechanism is provided by frequency conversion motor, slewing mechanism module and capsule filling institutions are driven by the two CAM intermittent mechanism of transmission system. Through inter-agency coordination and orderly movement, capsule filling machine can automatically complete capsule delivery, capsule separation ,capsule filling, capsule combination and so on. Its working process is shown in figure 1:

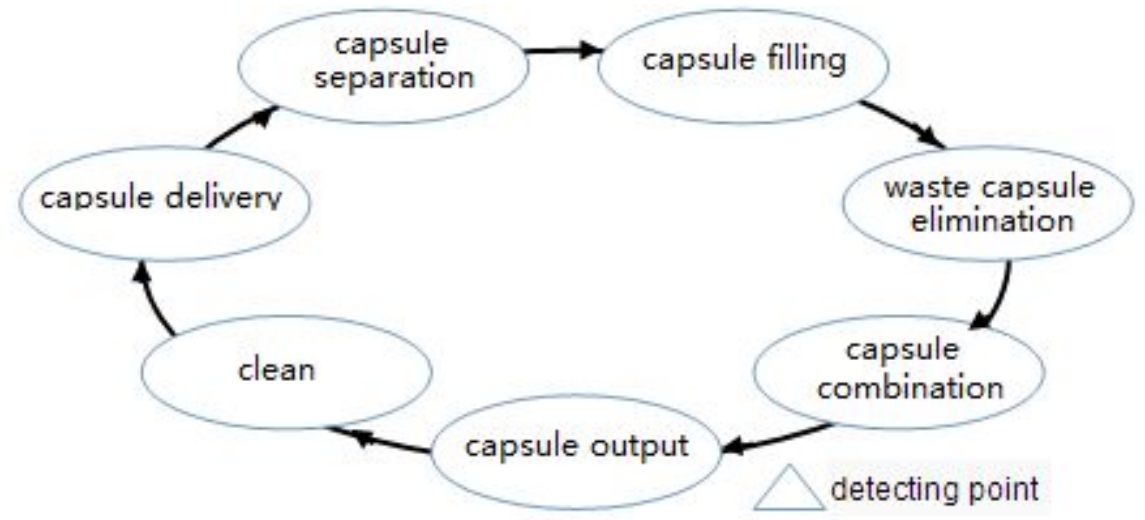

Fig.1 Working process of capsule filling machine

Filling machine in the above seven working process corresponds to seven different station to complete the corresponding work, in figure 1, testing point is the position for non-contact detection module .

\section{Non-contact online detection module}

Capsule filling machines made in China only have the production function without capsule counting function at present. The numbers back of capsule filling machine model represent production grain number per minute, such as the NJP - 1200 type refers to that the medicine machine can produce 1200 capsules per minute in theory. However, this figure is a rough estimation of the production quantity by the combination of running speed every minute of the rotary disk and the capsule hole number of the wheel[2]. Some damaged and no filling waste capsule will inevitably appear in the running process of filling machine, so the actual production quantity depends entirely on medicine machine working status: the better is medicine machine working state, the more closer is actual production number to the theory of production. When medicine machine's reliability reduces as the growth of the running cycle, with the rejection rate increasing, the number of actual production is far from the theory production. Non-contact online detection system makes up for the deficiency of the domestic medicine machine unable to count, it uses the optical fiber sensor to collectting signal, single chip microcomputer controliing, seven segment digital tube displaying, it can detect and show the medicine machine production in real-time. Non-contact online detection system takes the form of modules installed in the location between the back of capsule combination and the front of capsule out of medicine machine independently (as shown in figure 2 testing point). In this position, medicine machine 
has already eliminated the capsules by vacuum which cannot be normally opened, qualified capsules are ensured to be detected after capsule combination to make certain the accuracy of the count. Figure 2 is the nonlinear online testing module system block diagram. P1 port and P2.0 play a role as 9 input interface lines of the optical fiber infrared sensor. Detection signal of measuring position applies for interrupt signal by single chip microcomputer external interrupt 1 and acts as synchronous counting signal detection to launch the fibre infrared sensor data collection.

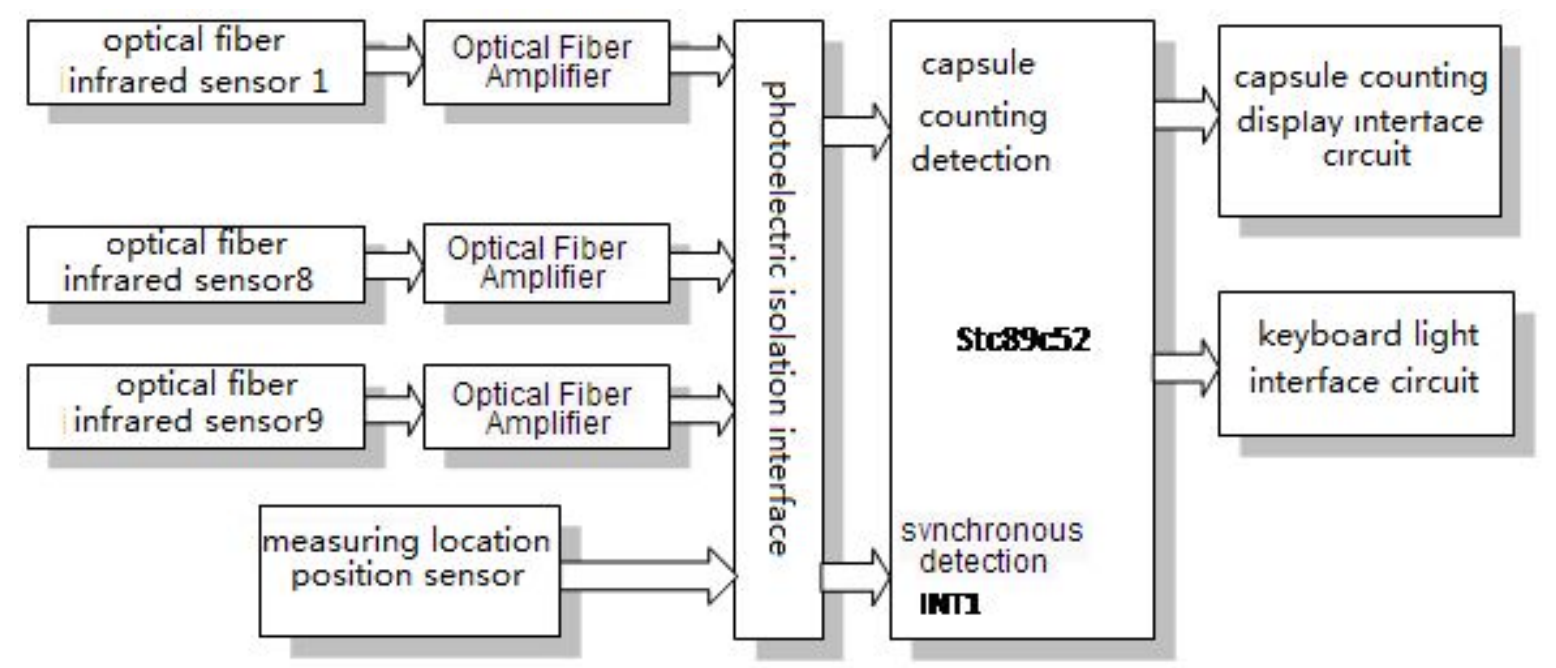

Fig. 2 Nonlinear online testing module system block diagram

\section{The key problems affecting non-contact online detection system}

The selection of the sensor. It is important to choose a suitable sensor to detect the capsule number accurately for collecting the signal accurately and in real-time and it directly affects the measurement precision of the system. A variety of types of sensors can be choosen to detect capsule number, contact type and non-contact type of sensor can both meet the needs of the measurement. According to the moving feature of the capsule filling machine and the workflow, non-contact sensor is not in contact with the object being measured and it is convenient to installate with small measurement error, so the non-contact photoelectric sensor is selected: diffuse optical fiber sensor. In order to make the signal transmission and amplification effectively, diffuse optical fiber sensor and optical fiber amplifier are used cooperatively. Optical fiber amplifier launch infrared irradiating position under test through the light optical fiber of the optical fiber sensor and receiving optical fiber of the optic fiber sensor receives the reflection signals. When light emitted by fiber optic sensor irradiates different types of objects, the roughness on the surface of the object, the color of the object and the distance from object to luminous point and so on will cause the difference of the reflected signal. Therefore, when the infrared light emitted by the sensor irradiates the position of filling capsules and unfilling capsules, reflection signals is not the same. Reflection of two different signals is sent to single chip microcomputer and identified by single-chip microcomputer ,then the number of output qualified capsules is shown.

On the other hand, the pitch of capsule filling machine placed capsule module is very small, it is about $10 \mathrm{~mm}$, that is to say, the center distance between the capsules and capsules is very small, in order to meet the requirements of measurement, the chosen sensor head size must 
be less than the pitch of capsule module, otherwise light emitted from the measuring head will not focus on single capsule points, but span to two capsules, this will affect the counting accuracy to cause measurement error. Based on this, measuring head size of the other photoelectric sensor is greater than capsule module pitch, only the optical fiber sensor can meet the demand of measurement. Its size is shown in figure 3, measuring probe width of the fiber optic sensor is far less than the pitch of capsule module, sensor length is also suitable for module installation requirements.

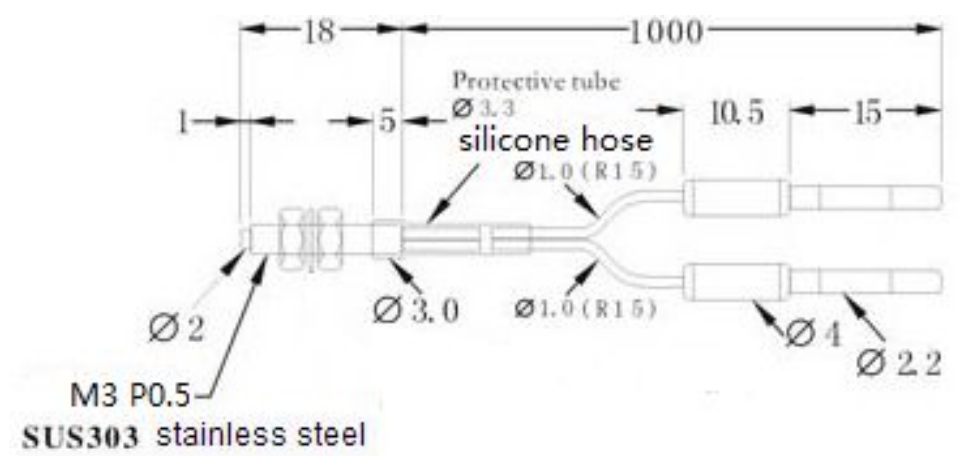

Fig. 3 Size of sensor probe compared with the pitch of the module diagram

Level angle calibration and sensitivity adjustment of optical fiber sensor. Not only the size of fiber sensor must match the capsule, but also its focal point of emission infrared must aim at measuring point, the height of the sensor placement and horizontal angle must satisfy the detection requirements of table 1. Based on nine holes capsule filling machine as the research object, when filling capsules are in measuring position of all the fiber optic sensor, the corresponding test ports shall be the low level. If test port is high level, that means the level elevation angle of the fiber optic sensor probe is not enough, the level elevation angle should be increased until the test port is low level. When unfilling capsules are in measuring location of all fiber optic sensor, the corresponding test ports shall be the high level; If test port is low level, that means the level elevation angle of the fiber optic sensor probe is too big, the level elevation angle should be reduced until the test port is low level.

Table 1 Optical fiber sensor calibration reference

\begin{tabular}{|c|c|c|c|c|c|c|c|c|c|}
\hline & $\begin{array}{l}\text { optical fiber } \\
\text { sensor } 1\end{array}$ & $\begin{array}{l}\text { optical fiber } \\
\text { sensor } 2\end{array}$ & $\begin{array}{l}\text { optical fiber } \\
\text { sensor } 3\end{array}$ & $\begin{array}{l}\text { optical fiber } \\
\text { sensor } 4\end{array}$ & $\begin{array}{l}\text { optical fiber } \\
\text { sensor } 5\end{array}$ & $\begin{array}{l}\text { optical fiber } \\
\text { sensor } 6\end{array}$ & $\begin{array}{l}\text { optical fiber } \\
\text { sensor } 7\end{array}$ & $\begin{array}{l}\text { optical fiber } \\
\text { sensor } 8\end{array}$ & $\begin{array}{l}\text { optical fiber } \\
\text { sensor } 9\end{array}$ \\
\hline test port & $\begin{array}{l}\text { low level } \\
\text { P1.0 }\end{array}$ & $\begin{array}{l}\text { low level } \\
\text { P1.1 }\end{array}$ & $\begin{array}{l}\text { low level } \\
\text { P1.2 }\end{array}$ & $\begin{array}{l}\text { low level } \\
\text { P1.3 }\end{array}$ & $\begin{array}{l}\text { low level } \\
\text { P1.4 }\end{array}$ & $\begin{array}{l}\text { low level } \\
\text { P1.5 }\end{array}$ & $\begin{array}{l}\text { low level } \\
\text { P1.6 }\end{array}$ & $\begin{array}{l}\text { low level } \\
\text { P1.7 }\end{array}$ & $\begin{array}{l}\text { low level } \\
\text { P2.0 }\end{array}$ \\
\hline $\begin{array}{l}\text { Corresponding } \\
\text { capsule state }\end{array}$ & unfilling & unfilling & unfilling & unfilling & unfilling & unfilling & unfilling & unfilling & unfilling \\
\hline test port & $\begin{array}{l}\text { high level } \\
\text { P1.0 }\end{array}$ & $\begin{array}{l}\text { high level } \\
\text { P1.1 }\end{array}$ & $\begin{array}{l}\text { high level } \\
\text { P1.2 }\end{array}$ & $\begin{array}{l}\text { high level } \\
\text { P1.3 }\end{array}$ & $\begin{array}{l}\text { high level } \\
\text { P1.4 }\end{array}$ & $\begin{array}{l}\text { high level } \\
\text { P1.5 }\end{array}$ & $\begin{array}{l}\text { high level } \\
\text { P1.6 }\end{array}$ & $\begin{array}{l}\text { high level } \\
\text { P1.7 }\end{array}$ & $\begin{array}{l}\text { high level } \\
\text { P2.0 }\end{array}$ \\
\hline
\end{tabular}

Because the system is installed in the medicine in the form of module, considering that when the detection module is normal on work, both capsule number should be displayed in real time, and the detection module can not influence the normal operation of medicine machine, so 
the sensor probe must keep a safe distance with medicine rotary disk and the distance of the probe and the testing point must be smaller than the effective measurement sensors. The effective measuring distance of the measuring probe and the testing point is determined by the sensitivity of the sensor and the sensitivity is adjusted by adjustment button on the optical fiber amplifier. Adjust sensitivity adjustment button repeatedly, considering sensor installation height, horizontal angle and the effective measurement three factors comprehensively, make the output signal of the sensor to fulfill the measurement requirements of high and low level. Sensors installation schematic diagram is shown in figure 4.

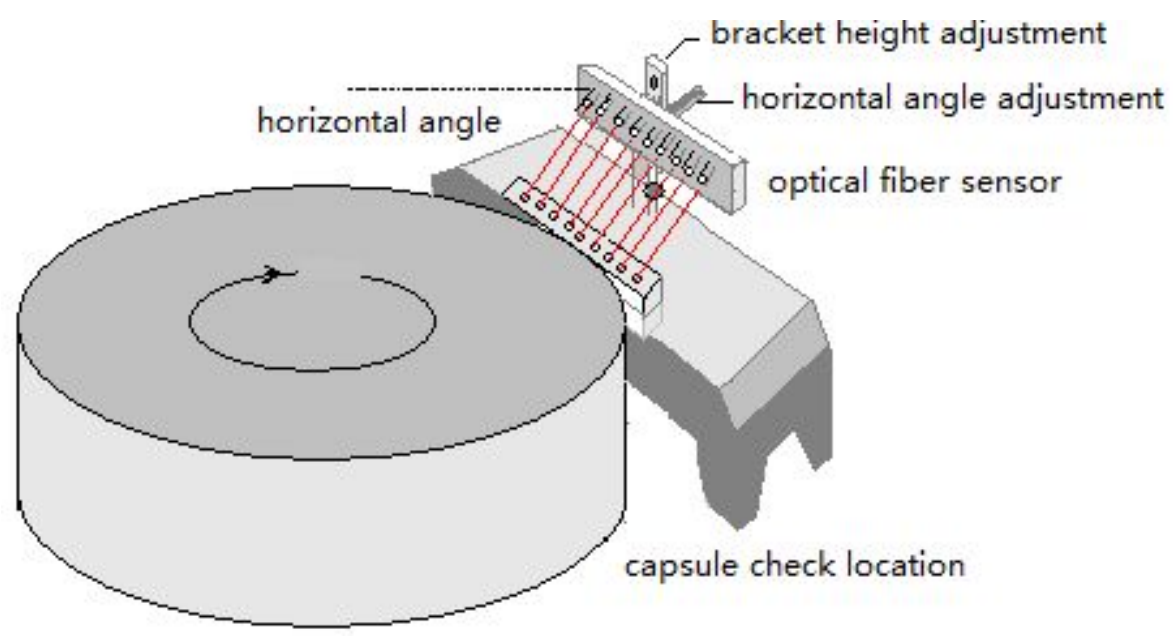

Fig.4 Sensors installation schematic diagram

Synchronous operation test. How to ensure the detection module count can be synchronized with the medicine machine operation is a crucial problem in the design of non-contact online detection module. Filling machine does both continuous movement and intermittent movement in working process, when capsule rotary disk runs continuously to check points, fiber optic sensor must read filling and non-filling information in the effective stay moment of the intermittent movement instantly and cannot have any delay, otherwise the effective time points of the rotary disk intermittent movement is missed ,the sensor will not be able to collect signals and cannot count the output. Photoelectric switch E18 - D50Nk is adopted in order to achieve the synchronization detection in the design to check location signals. E18 - D50Nk is anti-interference to visible light, cheap, easily assemble, digital outpu and do not need to undertake A/D conversion and can be directly connected to the microcontroller IO port: When check location arrives, photoelectric switch immediately transmits the filling and unfilling signal to the single chip microcomputer external interrupt 1 by photoelectric coupler, microcontroller reads data transmitted to $\mathrm{P} 1$ port by the optical fiber sensor after receiving interrupt application and starts the capsule counting function.

Autostop control circuit at the end of the counting. Non-contact online detection module can not only realize the capsule counting function, but also can set capsule counting value through the button control. When the number of qualified capsule produced by medicine machine is greater than the set value, the external interrupt 1 is prohibited. On the hardware, signals applying to interrupt are sent to SCM CPU: If the interrupt is allowed the switch is close; If the interrupt is forbidden ,the switch is open, sensor detection signal cannot apply for interrupt to 
CPU, counting stops. At the same time, SCM P0.7 port is reset by the instruction, low level is output, the triode breakovers saturatedly through the reverse driver, the current goes through the relay coil, normally-closed contacts of the relay disconnect, controlling medicine machine to stop running until the reset button is pressed, counting starts again. Figure 5 is relaying output control circuit diagram.

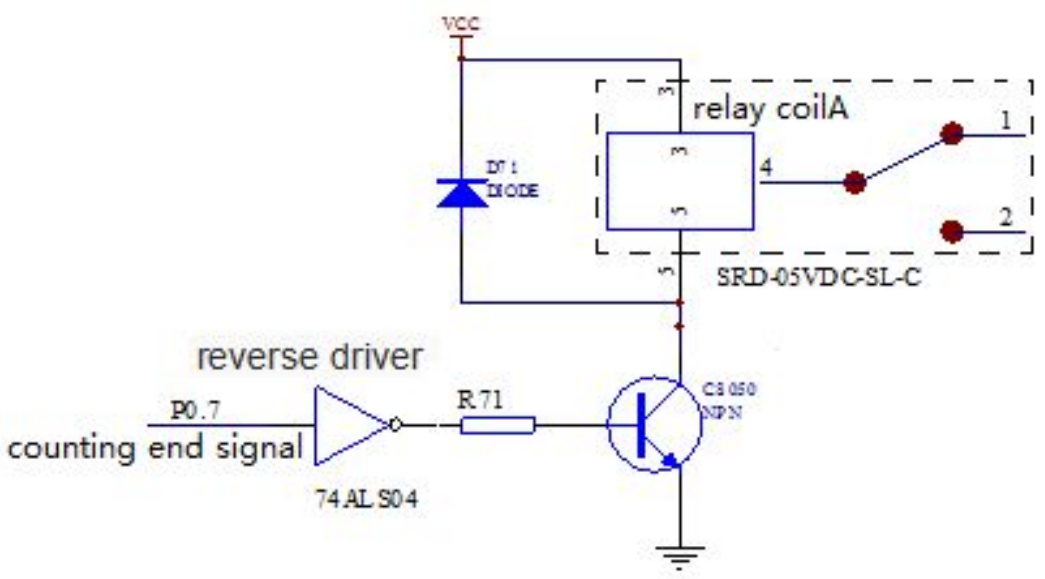

Fig.5 Relay output circuit

Anti-interference measures of online detection system. On the one hand, the anti-interference ability of the system must be improved, on the other hand, the interference component of data acquisition must be removed in order to get accurate count. Anti-interference measures reflect on the hardware design: external signals of sensor get into measurement system by photoelectric isolation; Sensors power supply and system power are independent of each other and there can be no interference between each other. Anti-interference measures reflect on the software design: digital filtering technology is adopted, the random disturbance component of data acquisition is gotten rid of. Digital filter algorithm is the algorithm that samples $\mathrm{N}$ times at each sampling period and compares multiple measured value continuously, chooses a frequent measured value as a valid value, so that random disturbance can be effectively removed[6,7]. Digital filtering flow chart for counting module is shown in figure 6. 


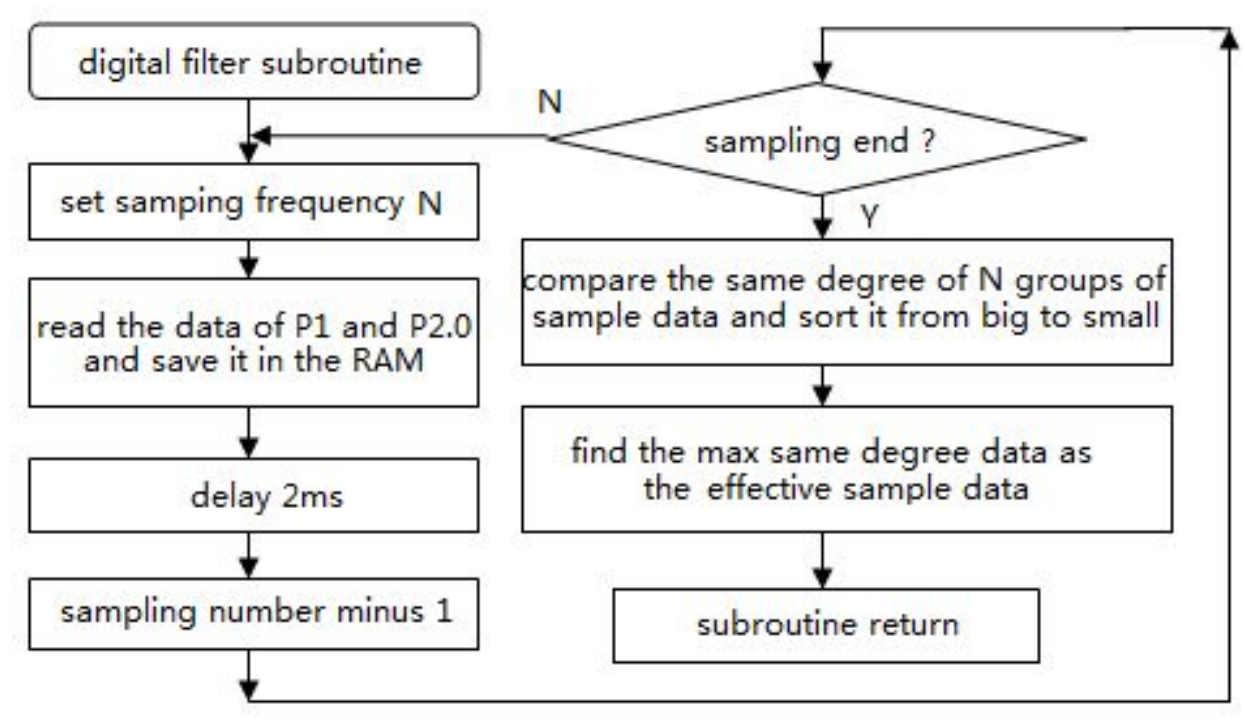

Fig.6 Digital filtering flow chart

\section{Summary}

The development and key technology research of non-contact online testing for drug metering control system can solve the problem of drug measuring of online inspection technology materially. It can not only display qualified drugs in the online, but also can control the medicine machine working condition. Its design concept is applicable for any type of drug machine and can be in any need to count the output of the capsule filling machine, It has a broad application prospect. In a word, the development of non-contact measuring online detection control system improves medicine machine automation and shortens the the gap of machine design and manufacture with foreign advanced medicine.

\section{Acknowledgement}

It is a project supported by excellent talents supporting plan in Liaoning province(the first level, LR2013062) ; public welfare projects in Liaoning province(2015004017) ; industrial research project of Dandong city technology bureau $(14207,09729)$ and Eastern Liaoning university scientific research fund project(2014-6).

\section{References}

[1] Guo Weidong, Virtual prototype technology and ADAMS application instance tutoria, Beijing,2008.

[2] Wen Zhaofang,SIMATIC S7-200 Programmable controller tutorial（the second edition) Beijing,2010.

[3] Wang Guihe, The dynamic analysis of the fully automatic capsule filling machine based on virtual prototype technology,Journal of eastern Liaoning university,Natural science edition, 
2012,19 (2).

[4] Wang Guihe,Zhang Baogang,Capsule filling machine plate CAM curve based on Matlab optimization,Journal of eastern Liaoning university,Natural science edition,2012,19 (3). [5] Li Quanli,Chi Rongqiang,Single chip microcomputer principle and interface technology, 2004.

[6] Feng Jianhua,Zhao Liang,Single chip microcomputer application system design and product development,Beijing,2004.

[7] Huo Mengyou,Single chip microcomputer principle and application of learning profile and antithesis, 2005. 